\title{
Previous Device Identifier
}

National Cancer Institute

\section{Source}

National Cancer Institute. Previous Device Identifier. NCI Thesaurus. Code C125195.

The identifier previously used to specify a medical device, prior to a change of the identifier. 